\title{
Search for New Type of Anticancer Drugs with High Tumor Specificity and Less Keratinocyte Toxicity
}

\author{
YOSHIAKI SUGITA ${ }^{1}$, KOICHI TAKAO ${ }^{1}$, YOSHIHIRO UESAWA ${ }^{2}$ and HIROSHI SAKAGAMI ${ }^{3}$ \\ ${ }^{1}$ Department of Pharmaceutical Sciences, Faculty of Pharmacy and \\ Pharmaceutical Sciences, Josai University, Sakado, Japan; \\ ${ }^{2}$ Department of Clinical Pharmaceutics, Meiji Pharmaceutical University, Tokyo, Japan; \\ ${ }^{3}$ Meikai University Research Institute of Odontology (M-RIO), Sakado, Japan
}

\begin{abstract}
Most current anticancer drugs have shown excellent therapeutic effects on human oral squamous cell carcinoma (OSCC), but they also produce potent cytotoxicity in normal oral keratinocytes. This review article summarizes our extensive research of tumor specificity and keratinocyte toxicity of nine groups of compounds synthesized in our laboratory. Among a total of 133 compounds, (E)-3-[2-(4hydroxyphenyl)ethenyl]-6-methoxy-4H-1-benzopyran-4-one [3] (classified as 3-styrylchromones), (E)-3-[2-(4chlorophenyl)ethenyl]-7-methoxy-2H-1-benzopyran [4] (classified as 3-styryl-2H-chromenes) showed the highest tumor specificity with the least keratinocyte toxicity. Compound [3] induced apoptotic cell death in a human OSCC cell line, possibly by down-regulating the glycerophospholipid pathway. Quantitative structure-activity relationship analysis demonstrated that the tumor specificities of [3] and [4] were well correlated with chemical descriptors related to their molecular size and lipophilicity. Chemical modification of these lead compounds by introduction of appropriate functional groups is a crucial step towards manufacturing new types of anticancer drugs with reduced keratinocyte toxicity.
\end{abstract}

Previous studies have focused on the mechanism of apoptosis induction by anticancer drugs rather than the

Correspondence to: Yoshiaki Sugita, Department of Pharmaceutical Sciences, Faculty of Pharmacy and Pharmaceutical Sciences, Josai University, Sakado, Saitama 350-0295, Japan. Tel: +81 492717254 , e-mail: sugita@josai.ac.jp and Hiroshi Sakagami, Meikai University Research Institute of Odontology (M-RIO), 1-1, Sakado, Saitama 350-0283, Japan. Tel: +81 492792758 (office), +81 492792787 (MRIO) (dial-in), Fax: +81 492855171, e-mail: sakagami@dent.meikai.ac.jp

Key Words: QSAR analysis, oral cancer, tumor specificity, keratinocyte toxicity, apoptosis, review. demonstration of their tumor specificity. Most anticancer drugs induce similar morphological changes to those observed during the developmental process (eliminating unnecessary tissues and harmful cells).

\section{Problems of Current Anticancer Drugs}

It is well known that administration of anticancer agents induces skin toxicity (1-7). This prompted us to re-evaluate the cytotoxicity and tumor specificity of anticancer drugs. For this purpose, we established an in vitro assay system, using four human oral squamous cell carcinoma (OSCC) cell lines (Ca9-22, HSC-2, HSC-3 and HSC-4), three human mesenchymal normal oral cells [gingival fibroblasts (HGFs), pulp cells (HPCs), periodontal ligament fibroblasts (HPLFs)] and two human epithelial normal oral cells [buccal mucosal human oral keratinocytes (HOKs) and primary human gingival epithelial cells (HGEPs)] (Figure 1). Cells were incubated for $48 \mathrm{~h}$ with increasing concentrations of test agents, and the relative viable cell number was determined by 3-(4,5-dimethylthiazol-2-yl)-2,5-diphenyltetrazolium bromide method. Tumor-selectivity index (TS) was determined by dividing the mean of the concentration that reduced the viable cell number by $50 \%\left(\mathrm{CC}_{50}\right)$ of each agent against normal cells by its mean $\mathrm{CC}_{50}$ against tumor cells (Figure $2 \mathrm{~A}$ ).

We first investigated the tumor specificity of anticancer drugs using OSCC cell lines and normal mesenchymal cells (MCs) (referred to as System 1). Many anticancer drugs, such as docetaxel, 5-fluorouracil (5-FU), methotrexate, mitomicin $\mathrm{C}$, etoposide, daunorubicin, doxorubicin, $\mathrm{SN}-38$ (active metabolite of irinotecan), camptothecin and gefitinib, showed excellent specificity (TS=10-1000) (Figure 2B) (8). This validated the present method for evaluating anticancer activity.

We next evaluated the tumor specificity of anticancer drugs using OSCC cell lines and normal epithelial cells (ECs.) (referred to as System 2). In this case, anticancer 
Human oral squamous cell carcinoma (OSCC) cell lines

Epithelial cells:

Ca9-22 (derived from gingiva tissue)

HSC-2, HSC-3, HSC-4 (derived from tongue)

\section{Normal human oral cells}

Mesenchymal cells (MC):

HGF: Human gingival fibroblasts

HPLF: Human periodontal ligament fibroblasts

HPC: Human pulp cells

Epithelial cells (EC):

HOK: Human oral keratinocytes

HGEP: Human gingival epithelium progenitors

Figure 1. Cells used for calculation of $\mathrm{CC}_{50}$ and tumor specificity (TS) value of previously investigated compounds.

A

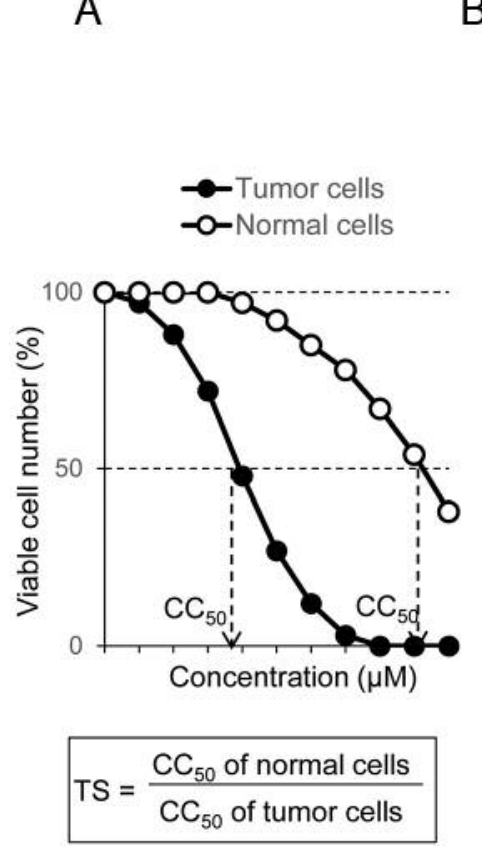

B

TS (OSCC vs. MC) System I

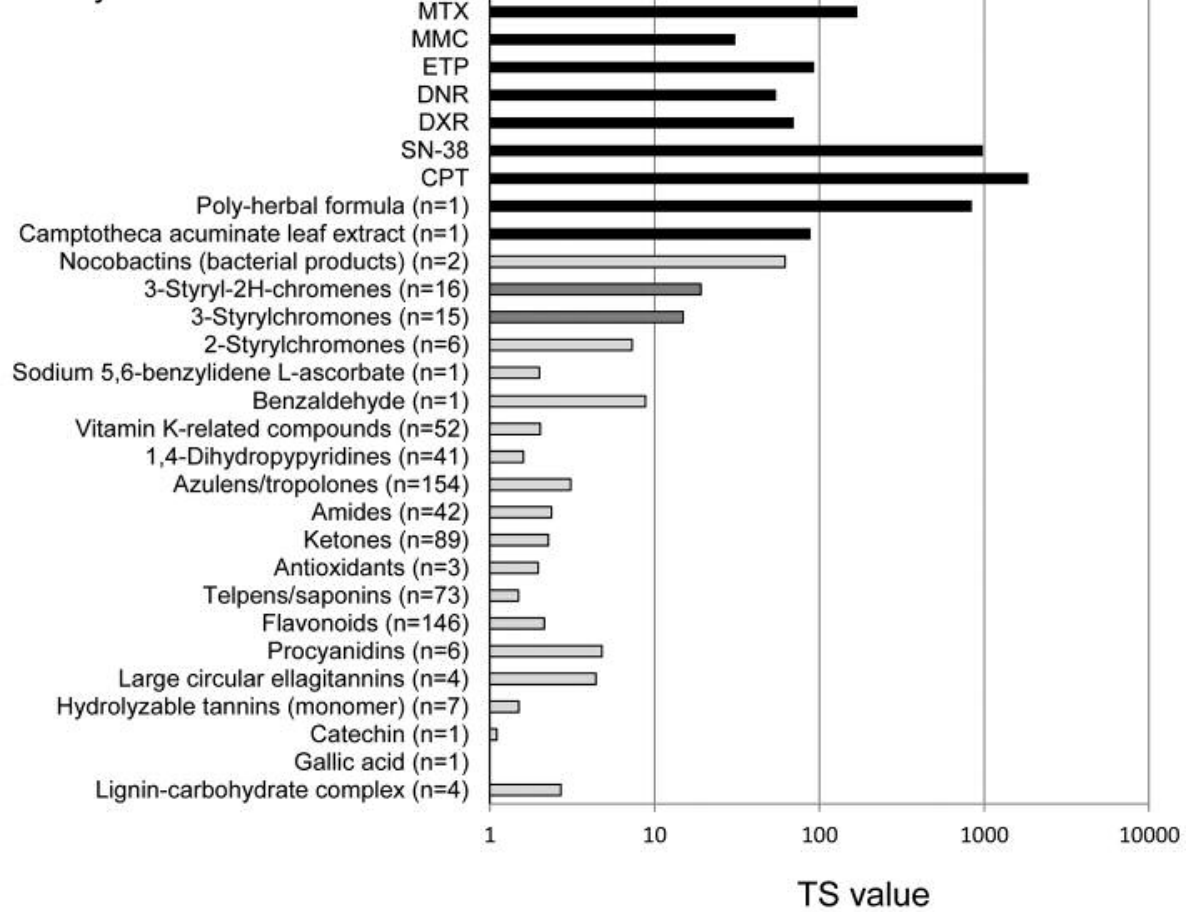

Figure 2. A: Exemplary calculation of tumor specificity (TS) value using the concentration that reduced the viable cell number by $50 \%\left(C C_{50}\right)$ values for tumor and normal cells. B: Comparison of TS values for antitumor agents and various natural and synthetic compounds. Data are cited from reference (8).

agents showed cytotoxicity to both of these cell types to comparable extents, producing a much lower TS value (9). It was unexpected that doxorubicin would induce apoptosis [loss of cell surface microvilli, chromatin condensation, nuclear fragmentation (Figure 3A) and caspase-3 activation (Figure 3B)] in HOKs (9). It is therefore imperative to explore new anticancer drugs with less keratinocyte toxicity.

\section{In Search of Antitumor Agents with Less Toxicity to Keratinocytes}

We have synthesized a total of 133 compounds, which are classified into nine groups, by introducing various functional groups into distinct backbone structures (Figure 4). The most potent compound in each group was: $(2 E)-3-(3,4$-dihydroxy- 

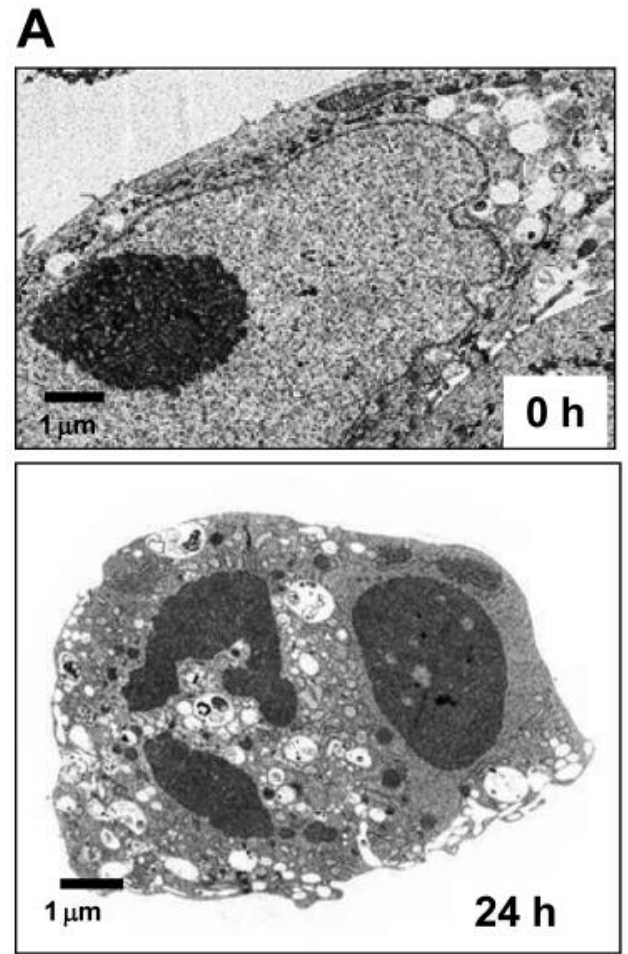

B
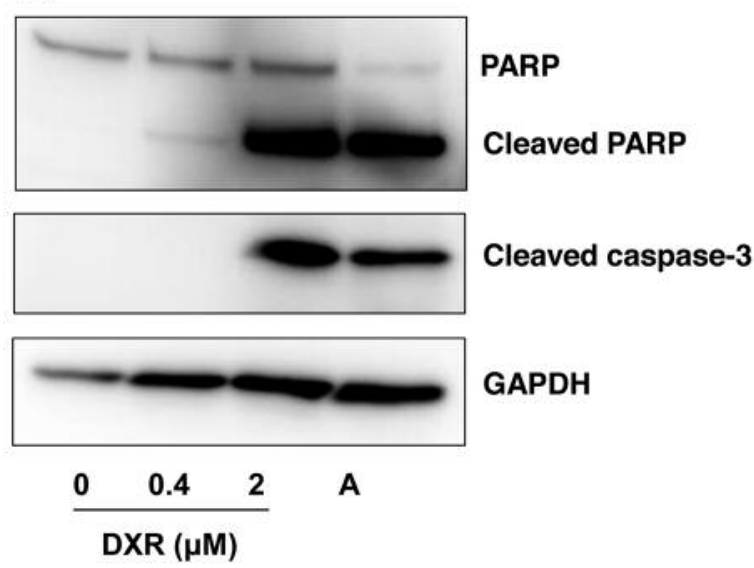

Figure 3. Keratinocyte toxicity induced by doxorubicin (DXR). HSC-2 cells were incubated for 0 or $24 \mathrm{~h}$ with $10 \mu \mathrm{M}$ doxorubicin $(A)$, or with different concentrations of doxorubicin $(B)$, and then processed for observation under transmission electron microscopy (A) or subjected to western blot analysis (B). Cited from (9) with permission. PARP: Poly (ADP-ribose) polymerase; GAPDH: glyceraldehyde 3-phosphate dehydrogenase.

phenyl)- $N$-[2-(4-hydroxyphenyl)ethyl]-2-propena-mide [1] (among 12 phenylpropanoid amides) (10), (2E,4E)- $N$-[2-(3,4dihydroxyphenyl)ethyl]-5-(3,4-methylenedioxyphenyl)-2,4pentadienamide [2] (among 12 piperic acid amides) (11), (E)3-[2-(4-hydroxyphenyl)ethenyl]-6-methoxy-4H-1-benzopyran- 4-one [3] (among 15 3-styrylchromones) $(12,13),(E)-3$-[2-(4chlorophenyl)ethenyl]-7-methoxy-2H-1-benzopyran [4] (among 16 3-styryl-2H-chromenes) (14), (Z)- $N$-[2-(3,4-dihydroxyphenyl)ethyl]-9-octadecenamide [5] (among 18 oleoylamides) (15), (3E)-2,3-dihydro-3-[(3,4-dihydroxyphenyl)methylene]-7methoxy-4H-1-benzopyran-4-one [6] (among 17 3-benzylidenechromanones) (16), (2E)-1-(2,4-dimethoxyphenyl)-3-(4methoxyphenyl)-2-propen-1-one [7] (among 15 chalcones) (17), (2E,4E)-5-(3,4-methylenedioxyphenyl)-2,4-pentadienoic acid (4-methoxyphenyl)methyl ester [8] (among 11 piperic acid esters) (18) and (2Z)-2-[(4-hydroxyphenyl)methylene]-3(2H)benzofuranone [9] (among 17 aurones) (19).

Among these nine compounds, [3] and [4] had the highest TS values (69.0 and 59.9, respectively), as assessed with System I [OSCC vs. MCs]. Their TS values (59.9-69.0) were comparable with that of doxorubicin $(63.7 \pm 95.0)$ and $5-\mathrm{FU}$ (13.1 \pm 21.1$)$, but greatly exceeded that of resveratrol $(\mathrm{TS}=2.4)$, a stilbene with anticancer activity (20) (Figure 4).

Compounds [3] and [4] also had the highest TS values when assessed with System II (OSCC vs. ECs: 204.5 and >85.1, respectively) (Figure 4). Their TS values were much higher than those of doxorubicin $(1.7 \pm 1.9)$ and 5-FU (1.4 \pm 1.1$)$ (Figure 4).

Treatment of HSC-2 cells with [4] induced mitochondrial vacuolization and inhibition of autophagy (as evidenced by loss of microtubule-associated protein 1A/1B-light chain 3 (LC3)II at an early stage, followed by the induction of apoptosis (as evidenced by cleavage of poly (ADP-ribose) polymerase and caspase-3). Compound [4] increased the intracellular levels of diethanolamine and cytidine diphosphate-choline, whereas it reduced the level of choline, suggesting down-regulation of the glycerophospholipid pathway (13).

\section{Estimation of TS by Chemical Descriptors}

Six descriptors that correspond greatly with cytotoxicity against normal cells $(\mathrm{N})$ and tumor cells $(\mathrm{T})$, and with tumor specificity $(\mathrm{T}-\mathrm{N})$ of nine groups of compounds are listed in Table I. Generally, these descriptors did not overlap with each other. Tumor specificity of 3-styrylchromones was well corrected with molecular size (12). T-N can be estimated by molecular diameter (largest value in the distance matrix defined by the elements Dij), vsurf_DD23 (interaction with hydrophobic probe assumed surrounding the molecule) and $\mathrm{R} 3 \mathrm{OH}$ (4'-hydroxy substitution in the phenyl group of styryl moiety) as: $\mathrm{T}-\mathrm{N}=0.607( \pm 0.169)$ diameter $-0.121( \pm 0.035)$ vsurf_DD23 + $1.11( \pm 0.235) \mathrm{R} 3 \mathrm{OH}-7.17( \pm 2.26)$, with $\mathrm{n}=15, \mathrm{R}^{2}=0.764$, $\mathrm{Q}^{2}=0.570 . \mathrm{s}=0.308$ (Figure 5A).

Tumor selectivity of 3-styryl-2H-chromenes correlated well with six descriptors (std_dim3, BCUT_SLOGP_1, vsurf_D4, vsurf_R, vsurf_D5 and E_oop) which reflect structure connectivity and conformation, hydrophobicity, surface rugosity and out-of-plane potential energy (Table I). The T-N value of [4] can be estimated using two descriptors (vsurf_R and E_oop) 
Table I. Chemical descriptors that correlate with 50\% cytotoxic concentration $\left(C C_{50}\right)$ against $\operatorname{OSCC}(T)$, normal oral cells $(N)$ and tumor specificity $(T-N)$ of previously investigated compounds.

\begin{tabular}{|c|c|c|c|c|}
\hline Category & $\mathrm{T}$ & $\mathrm{N}$ & $\mathrm{T}-\mathrm{N}$ & Ref. \\
\hline \multirow[t]{6}{*}{ Phenylpropanoid amide } & $\mathrm{G}^{\circ}$ & Acc. Polar area & Surface area & \multirow[t]{6}{*}{10} \\
\hline & $s^{\circ}$ & HOMO & \multirow[t]{5}{*}{ Max EIPot } & \\
\hline & $\mathrm{H}^{\circ}$ & Hardness & & \\
\hline & Surface area & $\log P(o / w)$ & & \\
\hline & Ovality & HBA coung & & \\
\hline & HBA count & & & \\
\hline Piperic acid amides & $\begin{array}{l}\text { PEOE_VSA_NEG } \\
\text { PEOE_VSA_FPOS } \\
\text { PEOE_VSA_FNEG } \\
\log P(\mathrm{o} / \mathrm{w}) \\
\text { a hyd } \\
\log S\end{array}$ & $\begin{array}{l}\text { vsurf_IW7 } \\
\text { vsurf_EWmin1 } \\
\text { vsurf_HB7 } \\
\text { vsurf_W7 } \\
\text { vsurf_HB6 } \\
\text { PEOE_VSA_FPOS }\end{array}$ & $\begin{array}{l}\text { vsurf_IW8 } \\
\text { PEOE VSA POL } \\
\text { PEOE_VSA+4 } \\
\text { PEOE_VSA_PPOS } \\
\text { PEOE_VSA PNEG } \\
\text { a nO }\end{array}$ & 11 \\
\hline \multirow[t]{2}{*}{ 3-Styrylchromones } & OMe at R1 & vsurf_DD23 & $\mathrm{OH}$ at $\mathrm{R} 3$ & \multirow[t]{2}{*}{12,13} \\
\hline & $\mathrm{OH}$ at R3 & G1u & $\begin{array}{l}\text { vsurf_DD23 } \\
\text { G2u }\end{array}$ & \\
\hline \multirow[t]{6}{*}{ 3-Styryl-2H-chromenes } & chi1v & std_dim2 & std_dim3 & \multirow[t]{6}{*}{14} \\
\hline & KierFlex & E_tor & SCUT_SLOGP_1 & \\
\hline & KierA1 & E_oop & vsurf_D4 & \\
\hline & SMR_VSA7 & std_dim3 & vsurf_R & \\
\hline & KierA3 & vsurf_A & vsurf_D5 & \\
\hline & Weight & SCUt_SMR 1 & E-oop & \\
\hline \multirow[t]{6}{*}{ Oleoylamides } & PEOE_VSA-0 & lip_don & AM1_dipole & \multirow[t]{6}{*}{15} \\
\hline & PM3_HOMO & E_tor & MNDO_dipole & \\
\hline & PM3_IP & SlogP_VSAO & PM3_HOMO & \\
\hline & SlogP_VSAO & Q_VSA_PPOS & PM3_IP & \\
\hline & lip_don & BCUT_PEOE_0 & dipole & \\
\hline & PEOE VSA+2 & b_single & $\log (o / w)$ & \\
\hline \multirow[t]{6}{*}{ 3-Benzylidenechromanones } & RDF095i & Mor03v & Mor3m & \multirow[t]{6}{*}{16} \\
\hline & RDF095u & Mor03m & Mor03v & \\
\hline & RDF095e & Mor09m & SpMAD_AEA & \\
\hline & vsurf_IW6 & G1u & vsurf_HB7 & \\
\hline & vsurfID7 & Mor03p & R3m+ & \\
\hline & vsurf_ID1 & R3m+ & Mor25v & \\
\hline \multirow[t]{6}{*}{ Chalcones } & HATS6 $p$ & CAT3D_10_DA & R6p & \multirow[t]{6}{*}{17} \\
\hline & vsurf_IW6 & RDF010s & R5v+ & \\
\hline & R6v & Q_VSA_PNEG & L3m & \\
\hline & R6p & PEOE_VSA-6 & VE2_H2 & \\
\hline & h-logs & B10[O-O] & L3s & \\
\hline & RDF035u & F10[0-0] & HATS6p & \\
\hline \multirow[t]{6}{*}{ Piperic acid esters } & R5i+ & CATS3D_17_AA & vsurf_DW13 & \multirow[t]{6}{*}{18} \\
\hline & R5u+ & rsynth & HATS5i & \\
\hline & $\mathrm{R} 2 \mathrm{e}+$ & CATS3D_13_AL & TDB08u & \\
\hline & SPH & CATS2D_04_AL & TDB08i & \\
\hline & JGI10 & CATS3D_16_AA & TDB08e & \\
\hline & $\mathrm{Dp}$ & JG10 & MATS5V & \\
\hline \multirow[t]{6}{*}{ Aurones } & E1u & vsurf_IW5 & HATS $6 p$ & \multirow[t]{6}{*}{19} \\
\hline & RDF010s & MLOGP & R6p & \\
\hline & CATS3D_04_DL & MLOGP2 & R6v & \\
\hline & Mor05i & HATS2p & $\mathrm{Gm}$ & \\
\hline & vsurf_HB4 & GATS1e & G3m & \\
\hline & vsurf_CW4 & $0 \%$ & HATS6V & \\
\hline
\end{tabular}

$\begin{array}{ll}\text { Red } & \text { Molecular size } \\ \text { Blue } & \text { Electrostatic } \\ \text { Green } & \text { Lipophilicity }\end{array}$




\begin{tabular}{|c|c|c|c|c|c|c|}
\hline Classification & $\begin{array}{l}\text { Number of } \\
\text { compounds } \\
\text { tested }\end{array}$ & Most potent compound & & $\begin{array}{l}\text { TS value } \\
\text { OSCC vc. MC } \\
\text { (System I) }\end{array}$ & $\begin{array}{c}\text { TS value } \\
\text { OSCC vs. EC } \\
\text { (System II) }\end{array}$ & Ref. \\
\hline Phenylpropanoid amides & 12 & & & $>3.4$ & & 10 \\
\hline Piperic acid amides & 12 & & 2 & $>10.7$ & & 11 \\
\hline 3-Styrylchromones & 15 & & & 69.0 & 204.5 & 12.13 \\
\hline 3-Styryl-2H-chromenes & 16 & & 4 & 59.9 & $>85.1$ & 14 \\
\hline Oleoylamides & 18 & & 5 & 15.5 & 2.3 & 15 \\
\hline 3-Benzylidenechromanones & es 17 & & 6 & $>55.2$ & 0.5 & 16 \\
\hline Chalcones & 15 & & & $>8.6$ & & 17 \\
\hline Piperic acid esters & 11 & & & $>10.5$ & & 18 \\
\hline Aurones & 17 & & 9 & & & \\
\hline & $\begin{array}{l}\text { otal number } \\
\text { (133) }\end{array}$ & & & $>9.7$ & & 19 \\
\hline $\begin{array}{l}\text { Doxorubicin } \\
5-F U \\
\text { Resveratrol }\end{array}$ & & & & $\begin{array}{c}63.7 \pm 95.0 \\
13.1 \pm 21.1 \\
2.4\end{array}$ & $\begin{array}{l}1.7 \pm 1.9 \\
1.4 \pm 1.1\end{array}$ & \\
\hline
\end{tabular}

Figure 4. Nine groups of compounds synthesized by chemical modification of back-bone structures present in naturally occurring compounds. OSCC: Oral squamous cell carcinoma; TS: tumor specificity; MC: mesenchymal cells; EC: epithelial cells.

A

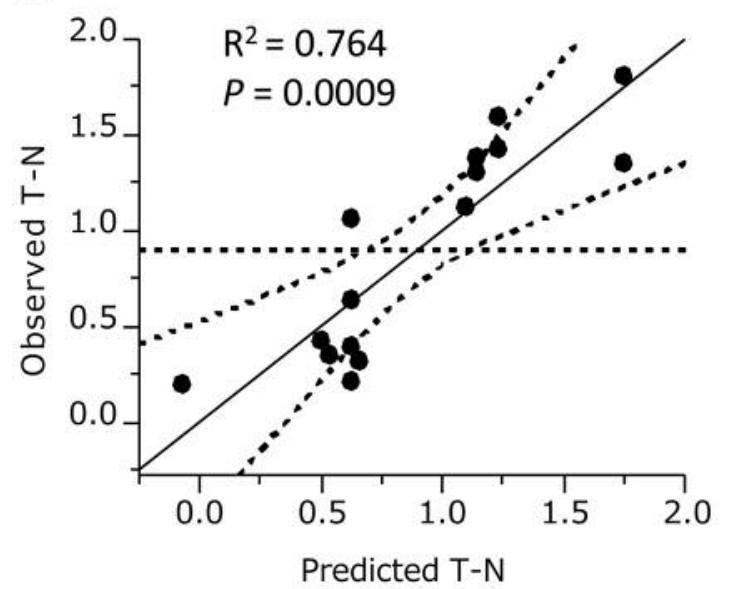

B

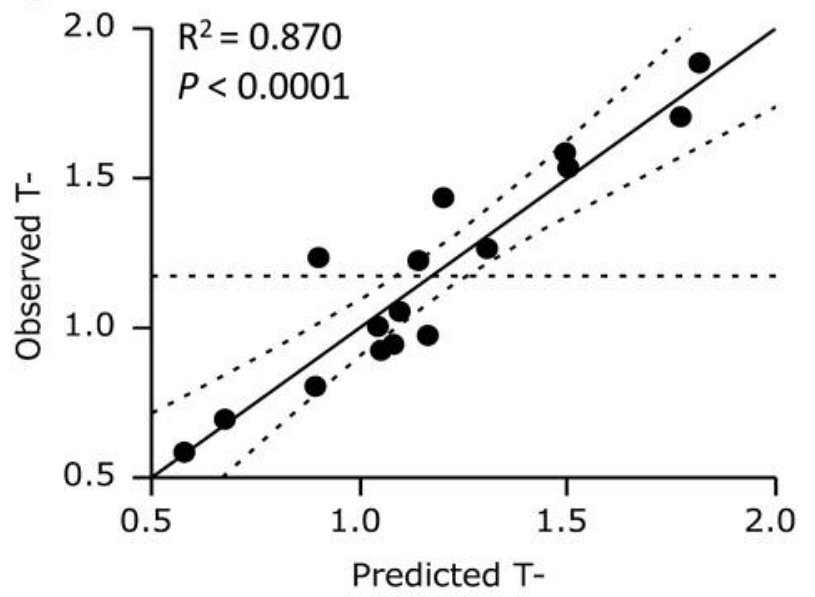

Figure 5. Multiple regression models for the estimation of the difference in cytotoxicity between tumor and normal cells (T-N) of 3-styrylchromones (A) and 3-styryl-2H-chromenes (B). Data are cited from references (12) and (14). 
as: $\mathrm{T}-\mathrm{N}=32.1( \pm 4.39)$ vsurf_R $+121( \pm 17) \mathrm{E} \_$oop $-46.1( \pm 6.2)$, with $n=16, R^{2}=0.870, Q^{2}=0.821, s=0.145$ (Figure 5B).

\section{Future Directions}

In our work, we have demonstrated that [3] and [4] are two new compounds that showed the highest TS and potencyselectivity expression values among the compounds tested, and they exhibited much less keratinocyte toxicity compared to doxorubicin and 5-FU (Figure 4). Chemical modification of these lead compounds by introduction of appropriate functional groups is a crucial step towards manufacturing new types of anticancer drugs with reduced keratinocyte toxicity.

\section{Conflicts of Interest}

The Authors confirm that there are no known conflicts of interest associated with this publication and there has been no significant financial support for this work that could have influenced its outcome.

\section{Acknowledgements}

This work was partially supported by KAKENHI from the Japan Society for the Promotion of Science (JSPS) (15K08111, 16K11519). The annual license of the statistical software, JMP Pro, was supported by the grant-in-aid of the Oncology Specialists Promotion Program by the Ministry of Education, Culture, Sports, Science and Technology, Japan.

\section{References}

1 Lulli D, Carbone ML and Pastore S: Epidermal growth factor receptor inhibitors trigger a type I interferon response in human skin. Oncotarget 7(30): 47777-47793, 2016.

2 Ferrari D, Codecà C, Bocci B, Crepaldi F, Violati M, Viale G, Careri C, Caldiera S, Bordin V, Luciani A, Zonato S, Cassinelli G and Foa P: Anti-epidermal growth factor receptor skin toxicity: a matter of topical hydration. Anticancer Drugs 27(2): 144-146, 2016.

3 Benjakul R, Kongkaneramit L, Sarisuta N, Moongkarndi P and Müller-Goymann CC: Cytotoxic effect and mechanism inducing cell death of $\alpha$-mangostin liposomes in various human carcinoma and normal cells. Anticancer Drugs 26(8): 824-834, 2015.

4 Do N, Weindl G, Grohmann L, Salwiczek M, Koksch B, Korting $\mathrm{HC}$ and Schäfer-Korting M: Cationic membrane-active peptides - anticancer and antifungal activity as well as penetration into human skin. Exp Dermatol 23(5): 326-331, 2014.

5 Moreno Garcia V, Thavasu P, Blanco Codesido M, Molife LR, Vitfell Pedersen J, Puglisi M, Basu B, Shah K, Iqbal J, de Bono JS, Kaye SB and Banerji U: Association of creatine kinase and skin toxicity in phase I trials of anticancer agents. Br J Cancer 107(11): 1797-1800, 2012.

6 Benedict AL, Knatko EV and Dinkova-Kostova AT: The indirect antioxidant sulforaphane protects against thiopurine-mediated photo-oxidative stress. Carcinogenesis 33(12): 2457-2466, 2012.

7 Fischel JL, Formento P, Ciccolini J, Etienne-Grimaldi MC and Milano G: Lack of contribution of dihydrofluorouracil and alphafluoro-beta-alanine to the cytotoxicity of 5'-deoxy-5-fluorouridine on human keratinocytes. Anticancer Drugs 15(10): 969-974, 2004.
8 Sakagami H: Biological activities and possible dental application of three major groups of polyphenols. J Pharmacol Sci 126(2): 92-106, 2014.

9 Sakagami H, Okudaira N, Masuda Y, Amano O, Yokose S, Kanda Y, Suguro M, Natori T, Oizumi H and Oizumi T: Induction of apoptosis in human oral keratinocyte by doxorubicin. Anticancer Res 37(3): 1023-1029, 2017.

10 Shimada C, Uesawa Y, Ishihara M, Kagaya H, Kanamoto T, Terakubo S, Nakashima H, Takao K, Saito T, Sugita Y and Sakagami H: Quantitative structure-cytotoxicity relationship of phenylpropanoid amide. Anticancer Res 34(7): 3543-3548, 2014.

11 Shimada C, Uesawa Y, Ishihara M, Kagaya H, Kanamto T, Terakubo S, Nakashima H, Takao K, Miyashiro T, Sugita Y and Sakagami H: Quantitative structure-cytotoxicity relationship of piperic acid amides. Anticancer Res 34(9): 4877-4884, 2014.

12 Shimada C, Uesawa Y, Ishii-Nozawa R and Ishihara M, Kagaya H, Kanamto T, Terakubo S, Nakashima H, Takao K, Sugita Y and Sakagami H: Quantitative structure-cytotoxicity relationship of 3-styrylchromones. Anticancer Res 34(10): 5405-5412, 2014.

13 Sakagami H, Shimada C, Kanda Y, Amano O, Sugimoto M, Ota S, Soga T, Tomita M, Sato A, Tanuma S, Takao K and Sugita Y: Effects of 3-styrylchromones on metabolic profiles and cell death in oral squamous cell carcinoma cells. Toxocol Rep 2: 1281-1290, 2015.

14 Uesawa Y, Sakagami H, Ishihara M, Kagaya H, Kanamoto T, Terakubo S, Nakashima H, Yahagi H, Takao K and Sugita Y: Quantitative structure-cytotoxicity relationship of 3-styryl-2Hchromenes. Anticancer Res 35(10): 5299-5308, 2015.

15 Sakagami H, Uesawa Y, Ishihara M, Kagaya H, Kanamoto T, Terakubo S, Nakashima H, Takao K and Sugita Y: Quantitative structure-cytotoxicity relationship of oleoylamides. Anticancer Res 35(10): 5341-5355, 2015.

16 Uesawa Y, Sakagami H, Kagaya H, Yamashita M, Takao K and Sugita Y: Quantitative structure-cytotoxicity relationship of 3benzylidenechromanones. Anticancer Res 36(11): 5803-5812, 2016.

17 Sakagami H, Masuda Y, Tomomura M, Yokose S, Uesawa Y, Ikezoe N, Asahara D, Takao K, Kanamoto T, Terakubo S, Kagaya $\mathrm{H}$, Nakashima H and Sugita Y: Quantitative structure-cytotoxicity relationship of chalcones. Anticancer Res 37(3): 1091-1098, 2017.

18 Sakagami H, Uesawa Y, Masuda Y, Tomomura M, Yokose S, Miyashiro T, Murai J, Takao K, Kanamoto T, Terakubo S, Nakashima H and Sugita Y: Quantitative structure-cytotoxicity relationship of newly synthesized piperic acid esters. Anticancer Res 37(11): 6161-6168, 2017.

19 Uesawa Y, Sakagami H, Takao K, Kagaya H and Sugita Y: Quantitative structure-cytotoxicity relationship of aurones. Anticancer Res 37(11): 6169-6176, 2017.

20 De Filippis B, Ammazzalorso A, Fantacuzzi M, Giampietro L, Maccallini C and Amoroso R: Anticancer activity of stilbenebased derivatives. ChemMedChem 12(8): 558-570, 2017. 